\title{
Microstructure Analysis of Titanium Alloys after Deformation by means of Asymmetric Incremental Sheet Forming
}

Lucie Novakova, Petr Homola, Vaclav Kafka

Aerospace Research and Test Establishment (VZLU), Beranovych 130, 19905 Prague - Letnany, Czech Republic. Email: 1.novakova@vzlu.cz

The contribution describes metallographic analyses assessment of titanium materials - a commercial purity titanium (Grade 2) and Ti-15V-3Cr-3Sn-3Al titanium alloy - after asymmetric incremental sheet forming (AISF) processing. Microstructure pattern and deformation mechanism of the titanium materials are given by the content ratio of $\alpha$ and $\beta$ phases that define formability of the resulting material. For the sake of description of the deformed parts from the view of mechanical properties, the microhardness measurements were performed on the samples taken from various zones of the resulting complex shape after the AISF processing. A distribution of deformation in dependence of the zone in the AISF part is similar for both experimental materials. A less pronounced microstructure refinement in the Ti-15-3-3-3 alloy is probably given by the springback occurrence in the case of this alloy.

Keywords: AISF, titanium alloys, sheet forming, microstructure, microhardness.

\section{Acknowledgements}

This work was supported by the EU project “Innovative Manufacturing of complex Ti Sheet Components" (INMA), grant agreement number 266208. The partners from Tecnalia (Fatronik, Spain) are acknowledged for performing the AISF experiments.

\section{References}

[1] BOYER, R. R. (1996). An overview on the use of titanium in the aerospace industry. Material Science and Engineering $A$, Vol. 213, pp. $103-114$.

[2] BUMBALEK, B., BUMBALEK, L. (2008). Surface Layer Properties of Titanium Alloys Ti6Al4V, Ti 7Al3, $5 \mathrm{Mo} 0,3 \mathrm{Si}$ after Milling and Grinding Operations and Their Influence on the Fatique. Manufacturing Technology, Vol. VIII, pp. $40-46$.

[3] DONACHIE, M. J. (2000). Titanium - a technical guide (2nd ed.). ASM International, USA.

[4] EMMENS, W. C., SEBASTIANI, G., VAN DEN BOOGAARD, A. H. (2010) The technology of Incremental Sheet Forming - A brief review of the history. Journal of Materials Processing Technology, Vol. 210, Issue 8, pp. 981-997.

[5] http://www.inmaproject.eu.

[6] JESWIET, J. et al. (2005) Asymmetric Single Point Incremental Forming of Sheet Metal. CIRP Annals - Manufacturing Technology, Vol. 54, Issue 2, pp. 88-114.

[7] KARASEVSKAYA, O. P. et al. (2003) Deformation behavior of beta-titanium alloys. Materials Science and Engineering A, Vol. 354, pp. 121-132.

[8] SEMIATIN, S. L. (2006). ASM Handbook, Volume 14B: Metalworking: Sheet Forming, pp. 656 - 669. ASM International, USA.

[9] WEISS, I., SEMIATIN, S. L. (1998) Thermomechanical processing of beta titanium alloys - an overview. Materials Science and Engineering A, Vol. 243, pp. 46-65.

[10] WYATT, Z., ANKEM, S. (2010) The effect of metastability on room temperature deformation behavior of $\beta$ and $\alpha+\beta$ titanium alloys. Journal of Materials Science, Vol. 45, pp. 5022-5031. 